\title{
A New Method for Measuring the Dynamic Shape Change of Platelets
}

\author{
Max-Joseph Kraus Erwin F. Strasser Reinhold Eckstein \\ Department of Transfusion Medicine and Hemostasis, University Hospital Erlangen, Germany
}

\section{Keywords \\ Platelet activation - Platelet function . \\ Platelets - Thrombocytes - Light microscopy . \\ Shape change}

\section{Summary}

Background: Platelet shape change is a dynamic process that has been classified in different types. Exact documentation of platelet structure needs an improved method of measuring platelet shape. Methods: $10 \mu \mathrm{l}$ of platelet-rich plasma (PRP) from anticoagulated whole blood (3.2\% buffered sodium citrate $0.105 \mathrm{~mol} / \mathrm{l})$ was put onto a glass slide covered with a cover slip. By use a of dark field light microscope connected with a CMOSCamera a photographic snap-shot was taken after 5 and $30 \mathrm{~min}$. Diameter of platelets and length of filopodia were measured with a self-developed plugin for ImageJ software. Statistic calculation was performed with Excel WinSTAT Microsoft software. Results: We showed a swelling of the granulomer from $2.06 \pm 0.56 \mu \mathrm{m}$ to $2.33 \pm$ $0.59 \mu \mathrm{m}(p<0.05)$, a reduction of pseudopodia $(2.10 \pm$ 0.94 vs. $1.78 \pm 1.04 \mu \mathrm{m} ; \mathrm{p}<0.05$ ) in conjunction with an increase of hyalomer diameter from $3.29 \pm 0.83$ to $3.50 \pm$ $0.85 \mu \mathrm{m}(\mathrm{p}<0.05)$, and an increase of pseudopodia length from $2.68 \pm 1.45 \mu \mathrm{m}$ to $3.67 \pm 1.79 \mu \mathrm{m}(p<0.005)$ in conjunction with an increase of hyalomer diameter from $6.58 \pm 1.91 \mu \mathrm{m}$ to $7.94 \pm 1.87 \mu \mathrm{m}(\mathrm{p}<0.05)$. Conclusion: We revealed and documented a dynamic change of platelet size and filopodia structure in PRP. This method allows an exact analysis of platelet size and surface structures.

\section{Schlüsselwörter \\ Thrombozytenaktivierung - Thrombozytenfunktion · Blutplättchen · Thrombozyten · Lichtmikroskopie · Formwandel}

\section{Zusammenfassung}

Hintergrund: Der thrombozytäre Formwandel (engl. shape change) ist ein dynamischer Prozess, für den eine Klassifikation nach Typen eingeführt worden ist. Für die genaue Dokumentation der dynamischen Änderungen der Plättchenstruktur ist eine verbesserte Messmethode notwendig. Methoden: $10 \mu \mathrm{l}$ plättchenreichen Plasmas (PRP) aus antikoaguliertem Vollblut (3,2\% gepuffertes Natriumcitrat, 0,105 mol/l) wurden auf einen Objektträger aufgebracht und mit einem Deckglas abgedeckt. Die digitale mikrofotografische Dokumentation 5 und 30 min nach der Präparation erfolgte unter Verwendung eines mit einer CMOS-Kamera verbundenen Dunkelfeldmikroskops. Durchmesser der Plättchen und Länge der Filopodien wurden mit einem selbstentwickelten Plugin für die Software ImageJ (NIH) vermessen. Die statistische Auswertung erfolgte mit Microsoft Excel WinSTAT. Ergebnisse: Ein Anschwellen des Granulomers von 2,06 $\pm 0,56$ $\mu \mathrm{m}$ auf $2,33 \pm 0,59 \mu \mathrm{m}(\mathrm{p}<0,05)$, eine Verkürzung der Pseudopodien $(2,10 \pm 0,94$ vs. $1,78 \pm 1,04 \mu \mathrm{m} ; \mathrm{p}<0,05)$ in Verbindung mit einer Zunahme der Hyalomer-Diameter von 3,29 $\pm 0,83$ auf $3,50 \pm 0,85 \mu \mathrm{m}(p<0,05)$ und eine Verlängerung der Pseudopodien von 2,68 $\pm 1,45 \mu \mathrm{m}$ auf 3,67 $\pm 1,79 \mu \mathrm{m}(\mathrm{p}<0,005)$ in Verbindung mit einer Zunahme der Hyalomer-Diameter von 6,58 \pm 1,91 $\mu \mathrm{m}$ auf 7,94 \pm $1,87 \mu \mathrm{m}(p<0,05)$ wird dargestellt. Schlussfolgerungen: Eine dynamische Änderung der Plättchengröße und Filopodien-Struktur wird gezeigt und dokumentiert. Die Methode erlaubt eine genaue Analyse und Dokumentation dynamischer Veränderungen von Plättchen im PRP.

\section{KARGER}

Fax +497614520714

Information@Karger.de

www.karger.com (c) 2010 S. Karger GmbH, Freiburg

Accessible online at:

www.karger.com/tmh

Dr. med. Max-Joseph Kraus

Transfusionsmedizinische und Hämostaseologische Abteilung

Universitätsklinikum Erlangen

Krankenhausstraße 12, 91054 Erlangen, Germany

Tel. +49 89 649-54228, Fax -63485

praxis@mjkraus.de,erwin.strasser@uk-erlangen.de 


\section{Introduction}

Blood platelets respond to many stimuli by changing shape from their resting, normal discoid form into more rounded structures possessing blebs and pseudopodia [1]. These morphological changes have been visualized using light- and electron microscopic techniques and are generally referred to as the platelet shape change (PSC) reaction. PSC follows a reproducible temporal sequence [2] and is a time- [3], temperature- [4], and ph-dependent [5] process mediated by calcium-dependent and calcium-independent signaling pathways [6]. The underlying processes of PSC are based on the gelsolin and ADF/cofilin enhanced rapid remodeling of actincytoskeleton [7].

If platelet rich plasma (PRP) from anticoagulated whole blood is put on a glass slide, platelets settle to the bottom and PSC is triggered by the contact to the glass surface [3]. The quantification of PSC is difficult, as platelets settle with different velocities [8] and the shape change reaction can be partly reversed [3, 8-9] or stopped [8] at any time. Non-fixed platelets are highly sensitive to a variety of influencing variables, for instance temperature [4], vibrancy, and light [3].

In 1976, Breddin [10] showed the time-dependent activation of platelets by the calculation of the percentage of pseudopodia-carrying cells. In the 1980s, Rosenstein [8] and Allen [3] categorized platelets into different morphological classes: an initial discoid stage one, a spheroidal stage two, an early spheroidal stage with few, short pseudopods present (stage three), a late pseudopodial stage with more numerous, longer pseudopods (stage four), a stage of fluctuation of the hyaline cytoplasma from the central region connecting the pseudopodia (stage five), a 'fried egg' stage with a central granule-containing hillock, the granulomer (stage six), and a final pancake configuration (stage seven) [8]. In 2000, Cenni et al. [11] quantified PSC of fixed and stained platelets based on spread area and distinguished between fully spread, round, and dendritic platelets.

According to platelet cytoskeleton research, we think that PSC should be described more detailed. We propose a set of diameters to describe the shape change reaction of living, non-fixated platelets in view of a computer-based automation of measurement and classification process.

\section{Material and Methods}

$2 \mathrm{ml}$ of citrated blood samples from 4 healthy volunteers were collected by venipuncture of the cubital vein by use of a 21-gauge needle (Sterican; B. Braun Melsungen AG, Melsungen, Germany). The blood was drained into a Seditainer collection tube (Becton Dickinson, Plymouth, UK) which was filled with a $3.2 \%$ buffered sodium citrate $0.105 \mathrm{~mol} / 1$ solution. The anticoagulated blood was not centrifuged but it was stored for $2 \mathrm{~h}$ in an upright position at room temperature $\left(22^{\circ} \mathrm{C}\right)$. After sedimentation of the buffy coat, the PRP was removed with a 20-gauge needle (Sterican; B. Braun Melsungen AG, Melsungen, Germany) and a small drop (10 $\mu \mathrm{l})$ was put on a glass slide (Paul Marienfeld GmbH \& Co. KG, Lauda-
Fig. 1. Draft of an activated platelet showing different diameters. Diameter of granulomer (1), longitudinal extension of pseudopodia (2), diameter of hyalomer (3), basal (5) and apical (6) lateral extension of pseudopods.

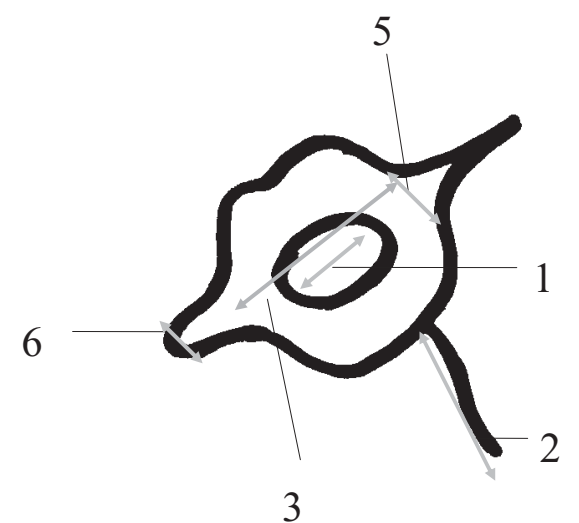

Königshofen, Germany). The drop of citrated PRP was covered with a cover slip $(20 \times 24 \mathrm{~mm}$, thickness: $0.13 \mathrm{~mm}$; Gerhard Menzel Glasbearbeitungswerk GmbH \& Co. KG, Braunschweig, Germany) which was lowered slowly and carefully onto the drop of PRP to complete dispersion of the PRP between glass slide and the cover slip.

\section{Microscopic Analysis}

A dark field microscope was used (Laborlux; Wild Leitz GmbH, Wetzlar, Germany) to show the surface of the platelets. The light strength was 100 W (halogen lamp, HLWS 5-A, 12 V, 100 W; Narva, Plauen, Germany). A dark field condenser (D. 1.19-1.44 OEL S11; Leitz, Wetzlar, Germany) and an objective with 100 -fold enlargement $(* 160 / 0.17$, PL Fluotar 100/1.32-0.60 OIL; Leitz, Wetzlar, Germany) were used. The microscope was mounted vibration-free. For the measuring and recording of the platelet shape, digital imaging was used. A CMOS-camera (Leica DFC 295; Leica Microsystems Ltd., Heerbrugg, Switzerland) was connected via a universal C-mount adapter to the microscope. The focus was set to the middle of the specimen.

\section{Image Processing}

Images were saved as tagged image file format. Consecutive images were imported as an image stack to ImageJ software (NIH ImageJ, Version 1.42-1). Image analysis and tracking of platelets was performed using a self-developed macro written in the ImageJ macro language and an associated self-developed plugin for ImageJ written in Java (JDK 7; Sun Microsystems GmbH, Berlin, Germany). After global scaling, platelet diameters were marked as region of interest (ROI) using straight line and segmented line selection tool.

Figure 1 shows the parameters of platelet shape, which have been marked as ROI: longest diameter of platelet granulomer (1), longitudinal extension of platelet pseudopodia (2), and longest diameter of hyalomer (3). For one platelet in sample 4, basal (5) and apical (6) lateral extension of pseudopodia have been marked. Each assigned ROI was categorized as mentioned above using keyboard shortcuts provided by the macro. ROI length and category were associated with the number of the currently analyzed platelet. Time since preparation was automatically calculated from the image creation date utilizing the loci bioformats java library (LOCI; Biophotonics Research Laboratory, University of Wisconsin-Madison, USA). ROI-coordinates, length value, category, time since preparation, slice number, and image creation date were automatically saved as comma-separated values for further processing in a database system. For printed publication, images were converted to negative using Irfan View software Version 4.00.

\section{Statistical Analysis}

Statistical calculation was performed with the Excel WinSTAT Microsoft software (Version 2009.1, Windows 2000). The data of the platelet parameters were displayed as mean and standard deviation. 

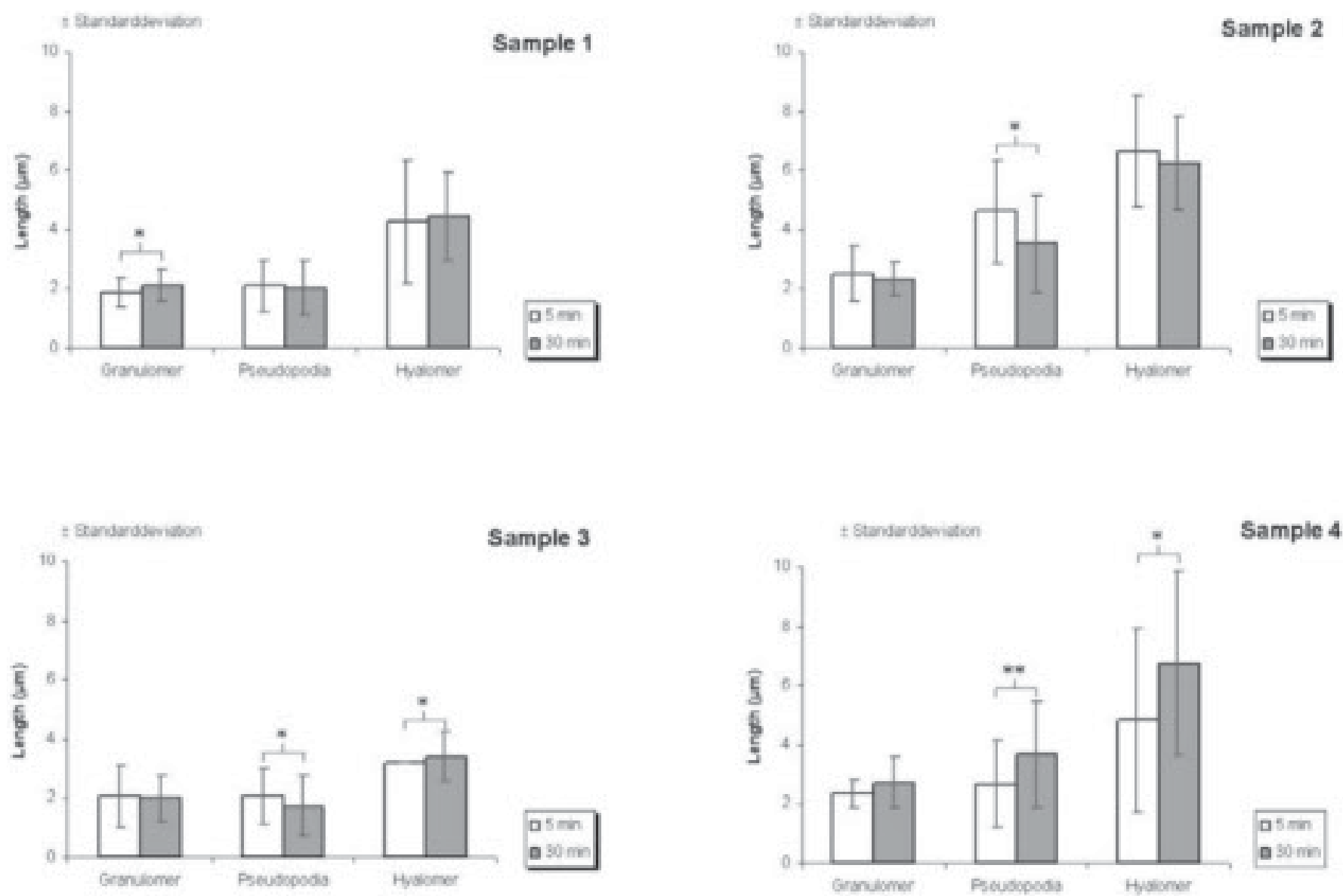

Fig. 2. Length (in $\mu \mathrm{m}$ ) of the regions of interest assigned to granulomer, pseudopodia, and hyalomer at 5 and 30 min after preparation. *p $<0.05$, $* * \mathrm{p}<0.005$.

\section{Results}

In four sample preparations we describe a new method to measure and quantify the platelet structure and its shape change. After preparation, platelets were allowed to settle for $30 \mathrm{~min}$ in order to get glass contact and therefore be activated. A digital image from the same region of the specimen was taken at $5 \mathrm{~min}$ and $30 \mathrm{~min}$ after preparation and was analyzed. 441 platelets and 585 pseudopodia were counted out, 290 platelets showed the extension of a hyalomer.

As diagrammed in figure 2, granulomers showed a significant swelling from $2.06 \pm 0.56 \mu \mathrm{m}$ to $2.33 \pm 0.59 \mu \mathrm{m}(\mathrm{p}<0.05)$ in sample 1. Otherwise, pseudopodia ( $2.32 \pm 0.94$ vs. $2.24 \pm$ $0.99 \mu \mathrm{m})$ and hyalomer $(4.49 \pm 1.19$ vs. $4.89 \pm 1.66 \mu \mathrm{m})$ did not show any significant change. In sample 2 , hyalomer and granulomer did not change significantly although the length of pseudopodia was reduced significantly from $4.71 \pm 1.78 \mu \mathrm{m}$ to $3.61 \pm 1.68 \mu \mathrm{m}(\mathrm{p}<0.05)$. In sample 3 , granulomer diameter did not change significantly but pseudopodia became significantly shorter $(2.10 \pm 0.94$ vs. $1.78 \pm 1.04 \mu \mathrm{m})$ and hyalomer diameter increased significantly from $3.29 \pm 0.83$ to $3.50 \pm 0.85$ $\mu \mathrm{m}(\mathrm{p}<0.05)$. In sample 4 , the granulomer did not change significantly while pseudopodia length increased highly sig- nificantly from $2.68 \pm 1.45 \mu \mathrm{m}$ to $3.67 \pm 1.79 \mu \mathrm{m}(\mathrm{p}<0.005)$, and the hyalomer diameter increased from $6.58 \pm 1.91 \mu \mathrm{m}$ to $7.94 \pm 1.87 \mu \mathrm{m}(\mathrm{p}<0.05)$. Figure 3 shows the assigned regions of interest.

One platelet of sample 4 has been followed in more detail for the first $9 \mathrm{~min}$ after preparation (fig. 4, 5). The initial swelling of the granulomer from 2.03 to $2.88 \mu \mathrm{m}$ in min 1 is followed by a decrease of granulomer diameter to a minimum of $1.75 \mu \mathrm{m}$ at $\min 8$. Hyalomer spreading begins at min 2 $(3.47 \mu \mathrm{m})$ and is increasing to a maximum of $6.71 \mu \mathrm{m}$ at $\min 8$. At min 2, also the formation of three pseudopods starts with a mean diameter of $1.51 \pm 0.37 \mu \mathrm{m}$ and increases undulating to a maximum of $2.76 \pm 0.18 \mu \mathrm{m}$ after $9 \mathrm{~min}$. Pseudopodia formation starts with a wide lateral basis that quickly narrows to $0.49 \pm 0.10 \mu \mathrm{m}$ after $5 \mathrm{~min}$. Apical lateral extension of the pseudopodia remains almost constant at about $0.28 \mu \mathrm{m}$.

\section{Discussion}

The data described above may give an idea of the variety of PSC reactions which could be observed in living, non-fixated platelets $30 \mathrm{~min}$ after preparation on a glass slide. While sam- 
Fig. 3. Details of sample 4 showing the assigned regions of interest. TIFF image, $799 \times 709 \times 24$ bytes per pixel.

Fig. 4. One platelet of sample 4 has been followed for the first 9 min after preparation. Regions of interest have been assigned.
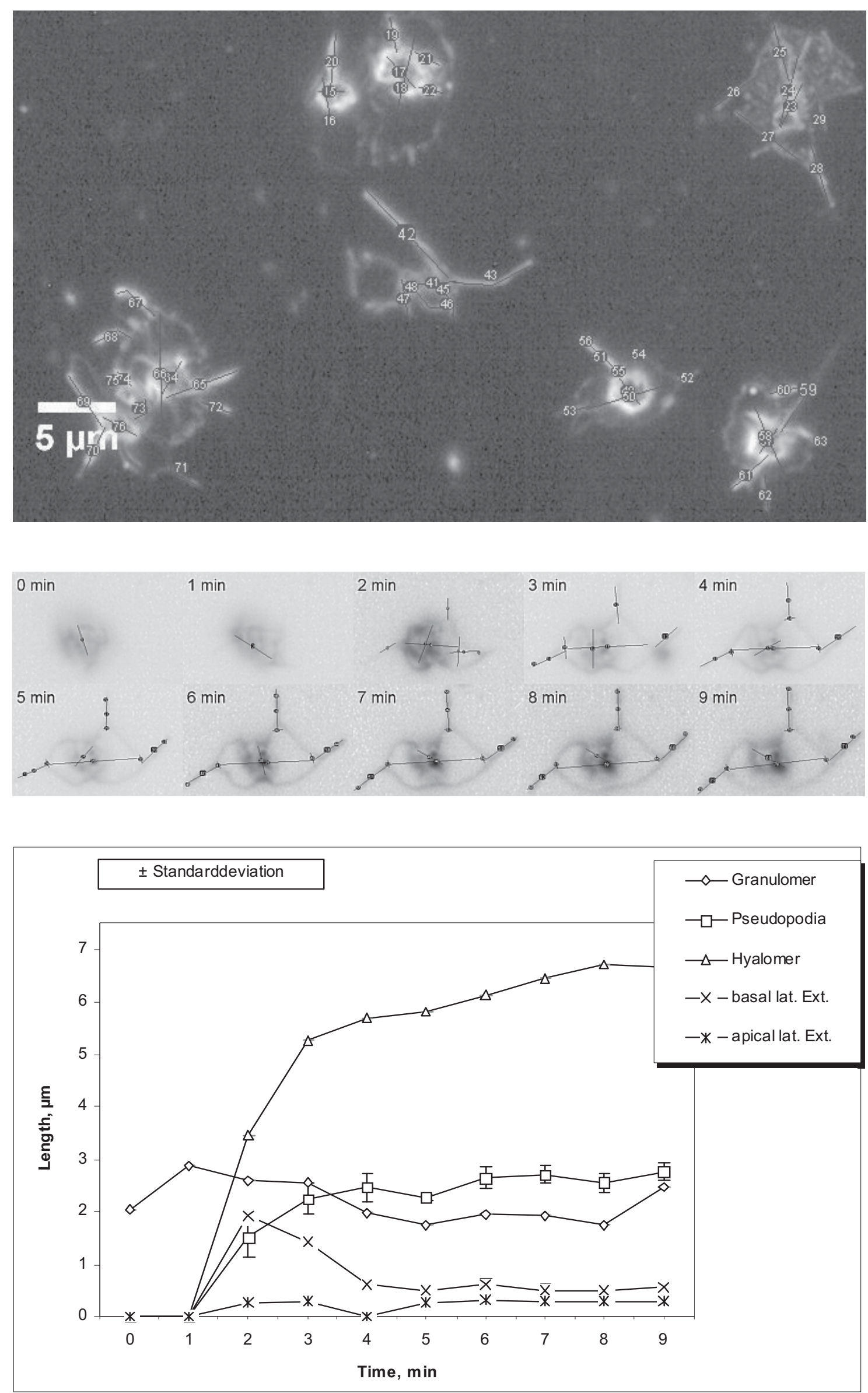
ple 1 shows the sole swelling of the granulomer and sample 2 shows the sole retraction of pseudopodia, sample 3 shows spreading of the hyalomer in conjunction with a retraction of pseudopodia, and sample 4 shows a spreading of the hyalomer in conjunction with the extension of pseudopodia. These results are consistent with the observations of other researchers: In 1979, Allen [3] diagrammed the extension and retraction of four pseudopodia of the same platelet and compared the extension and retraction of hyalomers and pseudopodia to the shroud-like pseudopodia of certain free-living amoebae [3]. In 1981, Rosenstein [8] also mentioned the extension and retraction of pseudopodia, and he explicitly pointed out that the spreading process of platelets may stop at any time and could even be partly reversed. Rosenstein found a time-dependent shift of the above cited morphological classes with a decrease in stages 3-5 and an increase in stages 6 and 7 [8]. As we did not use any of the established agents for controlled plateletactivation, such as ADP or collagen, we cannot explicitly assign the measured data to a specific stage of platelet activation.

The more detailed analysis of the one platelet of sample 4 can elucidate the possibilities of the presented method. On the one hand, it is now possible to quantify and visualize the dynamic morphological reactions during shape change. On the other hand, derived parameters, e.g. for velocity of pseudopod extension or hyalomer spreading, could be calculated. Linked to the results of platelet cytoskeleton research, our method could contribute to a better understanding of the rapid remodeling of the cytoskeleton in motile non-muscle cells.
We showed that the versatile shapes of living, non-fixated platelets can be quantified, diagrammed, and statistically analyzed by means of the measurement of clearly distinct diameters.

\section{Conclusion}

Dark field light microscopy shows an excellent contrast of platelet surface structures. By use of the ImageJ software for measuring platelet structure during shape change, we revealed and documented a dynamic change of platelet size and filopodia structure in PRP. The dynamic of shape change of living, non-fixated platelets upon activation on glass can be quantified, diagrammed, and statistically analyzed by the computerbased measurement of clearly distinct parameters. The proposed diameters could be used to measure and describe the stage of platelet activation more exactly. For the assignment of different stages of activation by measuring distinct diameters of the described parameters of platelet structure further studies are necessary, particularly by utilizing defined stimulating or inhibiting substances for platelet activation. This new standardized method allows an exact analysis of platelet size and surface structures which may be of further interest for different research subjects (i.e. platelet drug testing, platelet disorders).

\section{Disclosure}

The authors declared no conflict of interest.

\section{References}

1 Gear ARL, Polanowska-Grabowska RK: The platelet shape change, in Gresele CPPP, Vermylen J (eds): Platelets in Thrombotic and Non-Thrombotic Disorders: Pathophysiology, Pharmacology and Therapeutics. Cambridge, Cambridge University Press, 2002, pp 319-322.

2 Hartwig JH: The platelet cytoskeleton, in Michelson AD (ed): Platelets. New York, Academic Press, 2007, pp 75-86.

$>$ Allen RD, Zacharski LR, Widirstky ST, Rosenstein R, Zaitlin LM, Burgess DR: Transformation and motility of human platelets: details of the shape change and release reaction observed by optical and electron microscopy. J Cell Biol 1979; 83:126-142.
4 Maurer-Spurej E, Pfeiler G, Maurer N, Lindner H, Glatter O, Devine DV: Room temperature activates human blood platelets. Laboratory investigation 2001;81:581-592.

5 Leven RM, Gonnella PA, Reeber MJ, Nachmias VT: Platelet shape change and cytoskeletal assembly: effects of $\mathrm{pH}$ and monovalent cation ionophores. Thromb Haemost 1983;49:230-234.

6 Paul BZ, Daniel JL, Kunapuli SP: Platelet shape change is mediated by both calcium-dependent and -independent signaling pathways. Role of p160 Rho-associated coiled-coil-containing protein kinase in platelet shape change. J Biol Chem 1999; 274:28293-28300.

7 Southwick FS: Gelsolin and ADF/cofilin enhance the actin dynamics of motile cells. Proc Natl Acad Sci U S A 2000;97:6936-6938.
8 Rosenstein R, Zacharski LR, Allen RD: Quantitation of human platelet transformation on siliconized glass: comparison of 'normal' and 'abnormal' platelets. Thromb Haemost 1981;46:521-524.

9 Zobel CR, Woods A: Effect of calcium on the morphology of human platelets spread on glass substrates. Eur J Cell Biol 1983;30: 83-92.

10 Breddin K, Ziemen M, Grun H, Bauer O, Herrmann W: Formwandel und Funktionsverhalten der Thrombozyten nach der Blutentnahme. Onkohämostaseologie. 1976:297-304

11 Cenni E, Stea S, Cervellati M, Pizzoferrato A, Montanaro L: Quantitative evaluation by image analysis of platelet morphological modifications after contact with polyvinylacetate. Minerva Cardioangiol 2000;48:1-8. 